\title{
AN INVESTIGATION OF THE DIFFERENT TYPES OF THE INITIATION MOVE
}

\author{
Golebamang Galegane \\ Dr, University of Botswana, Botswana, GALEGANE@mopipi.ub.bw
}

\begin{abstract}
This research article addresses the use of the Initiation Move (I-Move) at higher learning and how it is developed. The overall purpose of this research article was to investigate the different types of the I-Move in Communication and Study Skills (CSS) classes at the University of Botswana (UB). In investigating the IMove to establish the different types, the Classroom Observations were used among nine lecturers from the seven faculties of the UB. The said Classroom Observations were captured by video recording the nine lessons in CSS classes of the UB. From the nine lessons observed, a transaction was selected for the analysis. In addition, the Initiation, Response, Feedback (IRF) moves were used to analyse the discourse from the Classroom Observations. The results indicate that a number of I-Move types namely; Informs, Directs, Checks, Questions were used and the most commonly used type was the 'lecturer questions'. Further, the results indicate a few instances where the students attempted to initiate the classroom talk, which in the process encourage communicative competence. The conclusion of the study was that the CSS classes are dominated by the lecturers. This is because during the I-Move, the lecturers take most of their time asking the students questions and informing them about the topics under discussion. The investigation of the I-Move was meant to shed some light on how the lecturers can initiate the classroom talk in an endeavour to develop the students' communicative competence.
\end{abstract}

Keywords: Initiation Move, Classroom Interaction, Acts, Pattern of Interaction

\section{INTRODUCTION}

The Initiation Move (I-Move) has been studied for over four decades now. The scholars of classroom interaction unanimously agree that the teacher is the one who initiates the classroom talk (e.g. Mercer, 2010; Sinclair \& Coulthard, 1975; Zhang, 2012). This research article, however, investigated the students' communicative competence in relation to the I-Move. The focus of this research article would mainly be on the types of initiations, which help to analyse their contribution to quality classroom interaction in higher education. In investigating the types of initiations used during classroom interaction, a closer look into the IMove was considered. Regarding the development of classroom interaction, the focal point was on how lecturers used the different types of the I-Move among the students. A review of the I-Move will assist in drawing conclusions regarding the quality of the said move in Higher Education.

The overall purpose of this research article was to investigate the different types of the I-Move in CSS classes at the University of Botswana. This was done in order to establish the effectiveness of the said types of the I-Move in developing students' communicative competence. To come up with findings for the research article, the following principal research question was asked: 'What kinds of initiations occur 
between students and lecturers in CSS classes?' The issue is being studied because there seem to be a problem with the quality and effectiveness of classroom interaction regarding the use of the I-Move in the University of Botswana classrooms. The foregoing will be used in this research article in order to analyse the use of the I-Move in CSS classrooms.

\section{THE ANALYTICAL TOOL}

The analysis in this research article focuses on the Initiation, Response, Feedback (IRF) analytical structure by Sinclair and Coulthard $(1975,1992)$. As Waring (2008) has stated, "IRF is a sequential feature, distinct in its prosodic packaging" (p. 578). This suggests that, in the classroom, interaction moves between the lecturers and the students in a certain logical order. Now, shifting to the focus of this research article, the IRF was used to mainly show how the I-Move was used by both the lecturers and students in an orderly and systematic way that reflected the different types of the I-Move. The investigation of the IRF will assist in identifying and assessing how the I-Move was used in CSS classes of the University of Botswana.

In further investigating the I-Move, previous studies (e.g. Smith., Hardman., \& Higgins, 2006) contend that, "an initiation, is usually in the form of a teacher question" (p. 444). From another perspective, White (2003) suggests that, the I-Move serves the purpose of opening up the classroom talk. It can be argued that for classroom talk to begin, the I-Move has to be used and in the process; questions, informs, checks and directs are used. Conclusively, the IRF analytical tool will help in contributing towards having quality and effective classroom talk during the teaching and learning process. The said three moves would explicitly show the pattern of interaction was reflected in the different lesson transactions.

\section{RESEARCH METHODOLOGY}

\section{The method}

This study was qualitative and it sought to find out more about the various types of the I-Move in CSS classes of the University of Botswana. Mukherji \& Albon (2018) suggest that it is important to classify the research design based on the nature of investigation. Grounded on the above scholars' observation, the aforementioned approach was used because the identified themes helped explain the different types of the IMove and this helped to determine the quality of classroom interaction in CSS classes. This was done by visiting the different CSSU classes in order to get first-hand information relating to the different types of the IMove.

\section{Participants of the Study}

A number of first year students who were enrolled for Communication and Study Skills took part in this study. The first year students were studied because they had just joined UB at the beginning of the first semester so, there was need to investigate their patterns in regard to the I-Move. The sample below was chosen from a population of 3483 students and 29 lectures. The students' sample was as follows; Science $1=30$, Science $2=35$, Business $1=47$, Business $2=41$, Social Sciences $=43$, Engineering and Technology $=22$, Humanities $=54$, Education $=54$, Health Sciences $=30$. The aforesaid students were selected by initially consulting the lecturers of the concerned classes. Upon the lecturers' consent, the concerned students were consulted by the researcher in the company of the lecturers. A consent form for both the students and the lecturers followed the initial class visits. From the lecturers' side, a sample of 7 lecturers and 9 classes were chosen. According to Mukherji \& Albon (2018, p. 30) a sample is, 'where cases are chosen that provide the information needed for the purpose of the research'. This suggests that a fewer number of participants is chosen from a large pool for use in carrying out the research. All the sampled students and lecturers stated above were used in the study because of their willingness to provide the research data.

Another aspect to acknowledge regarding the participants used herein, is the use of pseudonyms for the observed lecturers. The pseudonyms were used in order to maintain anonymity among the participants (Galegane, 2015). Additionally, Lysyanskaya., Rivest., Sahai, \& Wolf (1999) a pseudonym is a kind of system that allow users to interact with multiple classes anonymously, using pseudonyms. The above authors further reflect on the importance of this system. They point out that the pseudonyms cannot be linked with the real names, but are formed in such a way that a user can prove to the classes used about their relationship with another. As Lysyanskaya., et al points out, the use of pseudonyms attempts to prevent readers to identify the data with the participants of the study. This is seen as a good move as shows the respect for the participants who have willingly, decided to take part in the study.

\section{Research Instruments}

Classroom Observations were used to collect data for this research article. The classroom observation 
helped to examine the CSSU lecturers and their students interaction engagement in a natural setting (the classrooms). The Classroom Observations were also used in order to investigate the pedagogical practices and any challenges related to them. Researchers of classroom interaction (Tsui \& Law, 2007) argue that the above research instrument allows researchers to analyse the classrooms and also end up contributing to quality classroom talk.

\section{Data Collection}

During the lectures, the Classroom Observations were used to collect the data. The collected data was later analysed based on Sinclair \& Coulthard's $(1975,1992)$ system of analysis using the Initiation, Response, Feedback (IRF) analytical tool. Even though this research article investigated the I-Move, the IRF Moves are used because the three form a dialogic analysis system which the I-Move is part of. In reference to the data collection procedure, the data was collected by the researcher administering the Classroom Observations. During the observations, a video recorder was used to store all the information relating to classroom interaction in the sampled classrooms.

\section{Data Analysis}

In an endeavour to come up with solid findings, the data from the Classroom Observations were analysed by coding. For the above instrument, data were coded by classifying common information and relevant themes were set. According to MacLure; 2013, Gravetter \& Forzano (2018) coding involves looking for pattern or order in a body of data-such as field notes by identifying recurring themes. As mentioned in the above section, I analysed both the Classroom Observations using Sinclair \& Coulthard's $(1975,1992)$ analytical system using the IRF analytical tool. For this research article, the IRF was adjusted to qualitatively address the types of the I-Move only.

However, the above methods also had some limitations. In an example, the researcher visiting the classrooms seemed to make the sample not free. Despite the said limitations, the researcher worked on overcoming the limitation above by making the participants to feel very free. The researcher also allowed the participants to settle down before visiting the classes.

\section{RESULTS}

\section{The analysis of the I-Move in CSS classes}

\section{Introduction}

This research article has limited itself to the analysis of the quality of classroom interaction with particular focus on the types of the I-Move. The foregoing analysis would help to fully appreciate how initiation of classroom talk unfolded in the CSS classes. As part of the analysis, this research article will further illuminate on the quality of classroom interaction by considering the various types of I-Move in the said classes. Other studies of classroom interaction (e.g., Rappa \& Tang, 2018) assert that teachers predominantly delivered content information through the I-Move. Thus, the I-Move is important as it is used to start classroom talk. There are various ways used to initiate the classroom talk and these ways are discussed in-depth in the sub-sections that follow.

\section{Analysis of 'Informs'}

Lecturer 'Informs' are one of the important aspects of the I-Move. The concept of lecturer 'informs' was defined by Sinclair \& Coulthard (1975) when they stated that 'Informs' are part of the I-Move and are realized by a statement(s) and provides information. From the observed lessons, an example of 'Informs' was found in Lecturer Princess's lesson on "Reading Skills" when she said, "For all assignments at university level you are expected to read and then write because you are not expected to write compositions. You are expected to read and then write based on the reading. So we are looking at reading and looking at the reading process." (Teaching Exchange 2). During the 'Informs', the lecturers applied the initiation procedure by communicating knowledge to the students. These results suggest that the lecturers at times provided information to the students. Further, they explained the topics and sub-topics being taught in a number of ways. This noticeable aspect could be attributed to the fact that the lecturers wanted to lay the foundation regarding the subject matter.

\section{Analysis of 'Directs'}

The 'Directs' are meant to request a non-linguistic response (Sinclair \& Coulthard (1975). During the classroom talk, there were instances where the lecturers direct the students so that they end up making contributions to the I-Move. Two teaching approaches were used to maintain the directions to the students. 
One of these was to command the students to carry out some tasks such as writing. An example of such direction was found in lecturer Victor's lesson on note taking (teaching exchange 10) when he said, "I would take that down if I were you". Secondly, directions were provided by using pair or group discussions. This was illustrated in lecturer Glorious's lesson on listening and note taking (teaching exchange 34) when she said, 'but now I want us to break into four groups". It can be argued that even though the lecturers wanted to develop the students' oral communicative competence through the I-Move, this was used in relation to a variety of teaching methods.

\section{Analysis of 'Checks'}

A study on Initiations also address the lecturer 'Checks' as one of the important components that develop classroom talk. Conceptualised by Sinclair \& Coulthard $(1975)$ the 'checks' as, 'realised by a closed class of polar questions concerned with being 'finished' or 'ready', having 'problems' or 'difficulties', being able to 'see' or 'hear." (p. 40). This suggests that in 'checks' the question and the response will be closed because in most cases one word responses are used.

The lecturers in the CSS classes additionally initiated the classroom talk by checking on the students' understanding. This particular aspect was done in two ways, and one was by using rhetorical questions. These questions were rhetorical because no answer was expected from the students. One such example is found in lecturer Pretty's lesson on reading for academic purposes (teaching exchange 13) when she said, 'people who look at gender issues, for instance, most of the time they tend to be biased because they always look for women who are abused; and are always advocating for women's rights and so forth. Isn't it?' In agreement with some scholars that have analysed classroom interaction (e.g., Abd-Kadir \& Hardman, 2007; Zhang, 2012) these types of questions are also known as 'tag questions' and can be used to initiate classroom interaction as a way of checking that the students are following the preceding interaction. The above results suggest that lecturer checks can be responded to by silence.

Secondly, in some other fewer cases, the lecturers checked the students understanding by using, 'a closed class of polar questions' (Sinclair \& Coulthard, 1975, p. 40). Two functions surround these types of questions, one of them being that students responded chorally with 'yes' or 'no'. This was illustrated in lecturer Queen's lesson on reading (teaching exchanges 4-5), where she asked questions such as, 'do you understand what reading is all about? Do you understand what reading involves? Do you understand what I am saying?' These results suggest that lecturer checks co-exist with elicitations.

In CSS classes, it was also noted that the 'closed class of polar questions' were not always orally responded to. However, as the students worked in their groups, there were some instances where the lecturer-checks were responded to non-verbally with the accompaniment of some actions. Beforehand, the lecturers checked the structure of the groups or whether all students in the class belonged to a group. This was illustrated in lecturer Star's lesson on project writing when she checked, "do we have people who are four? Anybody four? Can you join them? Join them please. Sometimes we cannot avoid it; one or two groups will have more students." (teaching exchange 11). It can be claimed that lecturer-checks can be responded to through group formations in order to see that initiation of classroom talk develops effectually. A relationship exists between the said types of questions and the rhetorical ones, as there could be involvement of nonverbal cues. This is because 'actions' follow the spoken interaction from the lecturer.

\section{Analysis of 'Lecturers' Questions'}

In further analysing the I-Move, two types of questions (Open and Closed) were used by the lecturers. Sinclair and Coulthard (1975) defines the 'Questions' as a form of the I-Move that, 'requests a linguistic response' (p. 40). Thus questions are asked by the lecturers and/or the students to get more information about the issue being discussed. Analysing the two types of questions used by the lecturers helps in having a broader picture of how the I-Move was used in the classroom. Further, the examination of the two types of questions helps to justify why the said questions were used to initiate classroom talk in CSS classes.

This sub-section will briefly look at both the lecturers' open and closed questions. Examples of the open questions were found in Lecturer Glorious's lesson on Listening and Note Taking when she said, "what are the specific reasons why we listen? What do we benefit from Listening? (Teaching Exchange 9). From the above example, the question was open as the I-Move used solicited for a number of responses from the students. This suggests that the open questions developed the students' communicative competence.

Following the CSSU lecturers' open questions are the closed questions. During the I-Move, the closed questions restrict the students' development of their communicative competence. This type of question shows these results because the response is already known by the lecturer (Hardman, 2016). The example of a closed question was demonstrated in Lecturer Princess's lesson on Listening Skills when she said, "Do 
you understand everything that is said in this class?" (Teaching Exchange 25). These results suggest that if the students are asked questions where they have to display information known, either by both the lecturer and/or the students, short responses also occur. This is because the question does not help the students to be critical thinkers who can fully develop the classroom talk based on how the I-Move was used.

\section{Analysis of 'Students' Questions'}

Within the I-Move, there are the students' initiations which are in the form of questions. A look at both the questions used by the lecturers and the students helps in drawing conclusions that relate to the quality of classroom interaction in the CSS classes. Although the students' initiations were minimal when compared to the lecturers, it can be argued that the students were eager to contribute to the classroom talk. This view is supported by other scholars of classroom interaction (e.g., Chin, 2006; Beth \& Duncan, 2010) who stated that the students' contributions offered a window into their thinking.

An example of the students' questions was found in Lecturer Glorious's lesson on "Listening" and the focal point of the transaction was on the purposes of listening. One of the students asked a question by saying, "If anybody is sent to the social worker to be counselled; this falls under which purpose of listening? (teaching exchange 7). This example indicates that the students initiated the classroom talk and also used an open question to contribute to the classroom talk. However, the results of the lecturers' questions and those of the students still indicate that the CSS lecturers dominated the classroom talk.

\section{DISCUSSION}

This section seeks to qualitatively present the underlying meaning of the above results. The research article examines the different types of the I-Move and this was done by analysing data from the Classroom Observations.

\section{Lecturers' Contributions to the I-Move}

Generally, the results portrayed lecturer dominance in CSS classes of the University of Botswana. This is because, the lecturers engage the students in three major ways that result in lecturer dominance. One of these is that, normally the lecturers are the ones who open up the classroom talk. In some cases, after initiating the classroom talk, the students might assume that the lecturers should take the students through the whole lesson. Secondly, for most part of the lesson, the lecturers inform the students on the new aspects of the lesson. Finally, the lecturers ask the students some questions and if the questions are not responded to by the students, the lecturer then comes through and provides the information.

\section{Students' Contributions to the I-Move}

It is also clear from the results that there were glimpses of students' questions. These questions suggest that there is eagerness, although on minimal scale, of the students' contribution to the I-Move and the general classroom talk. Such pattern of interaction by the students is very important and it contributes to the students' communicative competence. Fletcher \& MacWhinney (2017) also claim that the dialogic steps are a way of developing the students' communicative competence. An additional argument to the foregoing glimpses of questions is that the students attempted and produced the target linguistic forms in meaningful and authentic contexts (Poza, 2018). These results are consistent with other scholars' findings (e.g. Chin \& Orsborne, 2008; Chung., Carter \& Sisco, 2012; Duffy, Warren \& Walsh, 2001; Winarti, 2017), that students can also use the I-Move in analysing classroom talk hence, the students questions in CSS classes. The students' questions help them to talk, think critically and end up improving their communicative competence.

An additional point relating to the students' initiations is that they contribute to the classroom talk that is well provided for. This is because, as the students orally contribute to the teaching learning process, that creates a balanced pattern of classroom interaction between the lecturers and the students. The above discussion is supported by Lefstein \& Snell (2014) who describe such students' steps as, 'rich and challenging classroom discourse'. From another related perspective, Savignon (2018) argues that communicative competence acts as a guide and evaluation of the learners. For both Savignon (2018; Lefstein \& Snell (2014) above, it can be claimed that, the students are capable of changing the existing educational status quo in relation to classroom talk.

Basing on the above discussion on the I-Move, this research would have an impact on future research. This is because other researchers would build on the current study and further investigate in various institutions, other aspects of the I-Move. Another importance of this study is that it would contribute to practice. The lecturers would be able to ask the students more open ended questions that will help the students to be critical thinkers. 


\section{CONCLUSION}

This research article aimed at investigating the different types of the I-Move in CSS classes at the University of Botswana (UB). This was done in order to establish the effectiveness of the said types of the I-Move in developing students' communicative competence. The results of this research article support the view that there is lecturer dominance of classroom talk in CSS classes of the University of Botswana. However, this could be minimised to help the students develop a rich communicative competence as they exchange ideas in the classrooms. Based on the previous point, the lecturers should try by all means to change the existing pattern of classroom interaction in the foregoing classes. This could be done by encouraging the students to contribute to the classroom discourse during lectures.

The data from this research article also revealed that there were a few instances where the students attempted to initiate the classroom talk. The students are developing an awareness that they can also develop the classroom interaction. This finding is important because it is supported by (Wilson, 2017) as an action that; aims to bring learning, takes account of where the learner is and regards the quality of what has to be learnt. This implies that during the teaching and learning process, the students can be given a chance to contribute to classroom interaction as this might help them to develop their oral communicative competence.

According to (Leung \& Mohan, 2004) findings such as lecturer dominance of classroom talk can shed some light on how lecturers can initiate the classroom talk in ways that the students can also contribute positively during pedagogical practices. This step will help to develop the students' communicative competence and eventually best practices in the use of the I-Move.

\section{REFERENCE LIST}

Abd-Kadir, J., \& F. Hardman. (2007). The discourse of whole class teaching: a comparative study of Kenyan and Nigerian Primary English lessons. Language and Education, 22 (1):1-15.

Beth, M., \& Duncan, B. D. (2010). "Big loud voice. You have important things to say": The Nature of Student Initiations During One Teacher's Interactive Read-Alouds. The Journal of Classroom Interaction, 45 (2): 20-29.

Chin, C. (2006). Classroom Interaction in Science: Teacher questioning and feedback to students' responses. International Journal of Science Education, 28 (11): 1315-1346.

Chin, C., \& Orsborne, J. (2008). Students' questions: a potential resource for teaching and learning science. Studies in Science Education, 44 (1): 1-39.

Chung, C., C. Carter, E. W., \& Sisco, L. G. (2012). Social Interactions of Students with Disabilities Who Use Augmentative and Alternative Communication in Inclusive Classrooms. American Journal of Intellectual and Developmental Disabilities, 117 (5): 349-367.

Duffy, J., Warren, K., \& M. Walsh. (2001). Classroom Interactions: Gender of Teacher, Gender of Student. Sex Roles, 45 (9/10): 579-593.

Fletcher, P., \& MacWhinney, B. (2017). Discourse Organization and the Development of Reference to Person, Space, and Time. In, the Handbook of child language. Wiley Online Library.

Galegane, G. (2015). A study of student-lecturer interaction in communication and study skills classes at the University of Botswana. Unpublished PhD Thesis: University of York.

Gravetter, F. J. \& Forzano, L. B. (2018). Research methods for behavioural Science. New York: Cengage.

Hardman, J. (2016). Tutor-student interaction in seminar teaching: Implications for professional development. Active Learning in Higher Education, 17 (1): 63-76.

Lefstein, A., \& Snell, J. (2014). Better than best practice: Developing teaching and learning through dialogue. London: Routledge.

Leung, C., \& Mohan, B. (2004). Teacher formative assessment and talk in classroom contexts: assessment as discourse and assessment of discourse. Language Testing, 21 (3): 335-359.

Lysyanskaya, A., Rivest, R. L., Sahai, A., \& Wolf, S. (1999). Pseudonyms Systems. In H. Heyes \& C. Adams 
(Eds). International Workshop on Selected Areas in Cryptography (pp. 184-199).

MacLure, M. (2013). Classification or wonder? Coding as an analytical practice in qualitative research. In R. Coleman., \& J. Ringrose (Eds.), Deleuze and Research Methods (pp.165). Edinburgh: Edinburgh University Press.

Mercer, N. (2010). The analysis of classroom talk: Methods and Methodologies. British Journal of Educational Psychology, 80 (1): 1-14.

Mukherji, P. \& Albon, D. (2018). Research methods in early childhood: An introductory Guide (3 ${ }^{\text {rd }}$ Edition). London: SAGE.

Poza, L. E. (2018). The language of ciencia: translanguaging and learning in a bilingual science classroom. International Journal of Bilingual Education and Bilingualism, 21:1-19.

Rappa, N.A., \& Tang, K. (2018). Integrating disciplinary-specific genre structure in discourse strategies to support disciplinary literacy. Linguistics and Education, 43, 1-12.

Savignon, S. J. (2018). Communicative Competence. In, The TESOL Encyclopedia of English Language Teaching, John Wiley \& Sons.

Sinclair, J. M., \& Coulthard, M. (1975). Towards an analysis of discourse: The English used by teachers and pupils. London: Oxford University Press.

Sinclair, J., \& Coulthard, M. (1992). Towards an analysis of discourse. In M. Coulthard (Ed.), Advances in Spoken Discourse Analysis (p.1-34). London: Routledge.

Smith, F.,Hardman, F., \& Higgins, S. (2006). The impact of interactive whiteboards on teacher-pupil interaction in the National Literacy and Numeracy Strategies. British Educational Research Journal, 32 (3): 443-457.

Tsui, A. B. M., \& Law, D.Y.K. (2007). Learning as boundary-crossing in school-university partnership. Teacher and Teacher Education. 23 (8): 1289-1301.

Waring, H. Z. (2008). Using Explicit Positive Assessment in the Language Classroom: IRF, Feedback, and Learning Opportunities. The Modern Language Journal, 92 (4): 577-594.

Wilson, E. (2017). Becoming a reflexive teacher (Third edition). In E. Wilson (Ed.), School-based research: A guide to education students (pp. 13-22). London: SAGE.

Winarti, W. A. (2017). Classroom Interaction: Teacher and Student Talk in International Class Program (ICP). KnE Social Sciences \& Humanities, 220-226

Zhang, P. (2012). Interactive Patterns and Teacher Talk Features in an EFL Reading Class in a Chinese University-A Case Study with Communicative Teaching Method. Theory and Practice in Language Studies, 2, (5): 980-988. 